\title{
La pobreza vista desde arriba \\ Una interpretación histórica desde el discurso peronista (1946-1955)
}

Noemí M. Girbal-Blacha

CONICET/UNLP/UNQ.

Quilmes Oeste (Prov. de Buenos Aires)

En 1946 y sobre "la arquitectura moral de la revolución del 4 de junio de 1943", el "coronel de los trabajadores", Juan D. Perón, conduce los destinos de la sociedad argentina. La redistribución del ingreso marca los perfiles de la Nueva Argentina, la que a través de un Estado dirigista y planificador propone poner la economía al servicio de la "justicia social". En ese contexto y sustentado por un discurso de confrontación que tiene como contrincantes al pueblo y a la oligarquía, el Estado populista se convierte en vocero de los reclamos y necesidades de los trabajadores, de los descamisados. Ellos son los protagonistas de la era peronista y el Estado su vocero. Este estudio analiza, a partir del discurso, las definiciones que el gobierno peronista formula acerca de la pobreza y de los pobres; precisa los medios que propone el Estado para contrarrestar la pobreza y formula una valoración de las connotaciones políticas que se otorga al concepto. El objetivo es hacer un balance del significado de la pobreza vista desde la esfera del poder de un gobierno nacionalista y popular y hacerlo a la luz del análisis histórico.

"No comprendía que habiendo pobres hubiese ricos y que el afán de éstos por la riqueza fuese la causa de la pobreza de tanta gente".

Perón, Eva: La Razón de mi vida, Buenos Aires, 1950, cap. 3, pág. 18

"La pobreza no es bella en ninguna parte; y si desagrada a mis amigos mexicanos lo que miran reflejado en ese espejo, es a ellos a quienes corresponde cambiar las realidades objetivas de su condición".

Lewis, Oscar: Antropología de la pobreza. Cinco familias, México, 1961, pág. 9

\section{Definiciones acerca de los pobres y la pobreza}

A mediados de la década de 1940 — y asentado en la "arquitectura moral de la revolución del 4 de junio de 1943"- el gobierno nacionalista y popular liderado por "el coronel de los trabajadores", Juan Domingo Perón, conduce los destinos de la Nación Argentina. ${ }^{1}$

1 Rouquie, Alain: Poder militar y sociedad política en la Argentina II. 1943-1973, Buenos Aires, 1982, pág. 46. 
La redistribución del ingreso, obtenido sustancialmente de la producción agraria, en favor del impulso - a través del crédito- de la pequeña y mediana industria que produce para un mercado interno en expansión, es también la garantía para el pleno empleo y marca los perfiles de la Nueva Argentina, que a través de un Estado dirigista, arbitral y planificador, propone colocar la economía al servicio de la "justicia social", aunque tratando por todos los medios de alejarse de cualquier referencia que lo emparentara con el marxismo. ${ }^{2}$ De ahí su preocupación por asociar el contenido social de su programa a la doctrina social de la Iglesia y su "poder moral". La función social de la propiedad que ésta sostenía desde la época de las encíclicas Rerum Novarum (1891) y Quadragesimo Anno (1931) — por ejemplo - permiten al peronismo presentar su propuesta como una alternativa equidistante del colectivismo y del liberalismo ortodoxo. La tercera posición se transformaría así en una atractiva opción para el justicialismo. ${ }^{3}$

En medio de esa situación y sustentado por un discurso de confrontación que se apoya en el pueblo y en la oligarquía en su rol de actores protagonistas $^{4}$ - de la Argentina peronista el primero y de la Vieja Argentina el segundo-, el Estado populista que lideran Juan Perón y Eva Duarte de Perón se propone "robustecer el hogar, la escuela y el trabajo por ser los grandes modeladores del carácter", al tiempo que se convierte en el vocero de los reclamos y las necesidades "de los hombres que trabajan", ${ }^{5}$ de los humildes, de los descamisados, de los pobres. Ellos son los protagonistas de la era peronista, es decir, "la multitud en estado dinámico", como "expresión democrática por excelencia", en tanto "es el recurso y la fuerza de los pequeños y de los anónimos", diría José M. Ramos Mejía en la Argentina del Centenario, en 1910, cuando se refería a la multitud como "una larva

2 Manual del Peronista, Buenos Aires, Los Coihues, 1988, págs. $23-24$ (1. a edic. 1948). Más datos de la economía peronista en Girbal-Blacha, Noemí M.: "Diagnóstico, legislación financiera y planificación económica (1946-1955). La trama política de una negociación perdurable", Revista de Historia del Derecho, 23, Buenos Aires, 1995, págs. 155-198; Lattuada, Mario J.: La política agraria peronista (1943-1983), Buenos Aires, 1986; Novick, Susana: I.A.P.I.: auge y decadencia, Buenos Aires, 1986; y Girbal-Blacha, Noemí M.: "Estado, campo e crédito na Argentina Peronista: Confrontaçao Pública, acordos privados (1946-1955)", en Mendonça, Sônia e Motta, Márcia: Naçao e poder: as dimensoes da História, Niteroi/RJ, 1998, págs. 127-141.

3 Gerchunoff, Pablo y Llach, Lucas: El ciclo de la ilusión y el desencanto. Un siglo de políticas económicas argentinas, Buenos Aires, 1998, págs. 169-172.

4 Ipola, Emilio de: Ideología y discurso populista, México, 1982. Laclau, Ernesto: "Populismo y transformación del imaginario político en América Latina", Cuadernos de la Realidad Nacional, 3, Quito, 1988.

5 Manual del ..., pág. 20. 
que evoluciona, o mejor que eso, un embrión que parece mantenerse en estado estático, esperando la oportunidad de sus transformaciones". ${ }^{6}$

En la Argentina peronista la hora de la transformación parece haber llegado. El discurso del poder así lo explicita y lo reitera, cuando el Estado a través de su política de previsión social procura "asegurar el mínimo indispensable para vivir" y se aferra a la "asistencia social como el principio que asegure que el hombre debe tener un salario para comer, habitar y vestirse"; ya que — agrega el Manual del Peronista_ "sobre el dolor y la miseria nada se construye". ${ }^{7}$

Si bien suele existir consenso acerca de las condiciones objetivas de la pobreza - un término polarizado, polisémico y que remite a condiciones alternativas - no ocurre lo mismo cuando se pondera la situación social que ella implica y que fluctúa con los tiempos. Dada una situación de carencia de bienes y servicios con efectos psicofísicos para el afectado, puede decirse que "la pobreza irrumpe como contexto y como vivencia", y que puede entenderse en dos sentidos: como carencia absoluta o en relación con privaciones relativas, es decir, las carencias confrontadas con algún "grupo de referencia". ${ }^{9}$ En cualquier caso, la pobreza, como otros problemas sociales, no encuentra una explicación sólo en cuestiones económicas o en desajustes en la dinámica de crecimiento. No es difícil advertir entonces la estrecha vinculación que existe entre la cuestión social, las mediaciones del sistema de poder y las decisiones estatales en relación con las condiciones de vida.

6 Ramos Mejía, José M.: Las multitudes argentinas. Estudio de psicología colectiva, Buenos Aires, 1977, págs. 221 y 233 (1. ${ }^{\text {a }}$ edición 1910). Sobre el discurso puede consultarse: Girbal-Blacha, Noemí M.: "Dichos y hechos del gobierno peronista (1946-55). Lo fáctico y lo simbólico en el análisis histórico", Entrepasados. Revista de Historia, 13, 1997, págs. 63-78. Otros aportes al estudio del peronismo en Waldmann, Peter: El peronismo, 1943-1955, Buenos Aires, 1981; Buchrucker, Cristian: Nacionalismo y peronismo. La Argentina en la crisis ideológica mundial (1927-1955), Buenos Aires, 1987, cap. 4; Tur Donatti, Carlos M.: "La utopía criolla en el siglo XX: cultura y política del nacionalismo restaurador en Argentina", en Revista de Ciencias Sociales 3-4, vol. XXX, Puerto Rico, mayo 1995, págs. 165-203; Castro Rea, Julián, Ducantezeiler, Graciela y Faucher, Philippe: "La tentación populista: Argentina, Brasil, México y Perú", Foro Internacional. Revista trimestral del Colegio de México, 2, vol. XXXI, octubre-diciembre 1990, págs. 252-285; Quattrocchi-Woisson, Diana: "Les populismes latino-américains à l'èpreuve des modèles d'interprétation européens", Vingtième Siècle. Revue d'Histoire, 56, oct.-dec. 1992, págs. 161-183; y Sidicaro, Ricardo: Juan Domingo Perón, Buenos Aires, 1996.

7 Manual del ...., págs. 20, 27 y 33.

8 Fernández Pardo, Carlos A.: Economía y sociedad de la pobreza en las provincias argentinas, Buenos Aires, 1984, págs. 7-8.

9 Moyano Llerena, Carlos: La pobreza de los argentinos. La decadencia nacional y la esperanza de un futuro distinto, Buenos Aires, 1987, págs. 148-150. 
"Un día oí por primera vez de labios de un hombre de trabajo que había pobres porque los ricos eran demasiado ricos; y aquella revelación me produjo una impresión muy fuerte"; así expone y define Eva Perón "el tema de mis soledades", ${ }^{10}$ como ella consideraba a la pobreza, inscripta en el marco seductor del discurso populista que junto a Juan Perón modela, en su afán por difundir la doctrina y las realizaciones que le dan credibilidad social al régimen.

¿Cómo describe el peronismo esta "pobreza sensible", que si bien comprende a zonas rurales y urbanas, se arraiga sustancialmente en la ciudad y en las áreas suburbanas del Gran Buenos Aires? Su visión de la pobreza se identifica con "esas colmenas de arquitectura baja que son los barrios pobres", aquéllos de "ranchos de paja y barro, casillas de latón, algunas macetas de flores y algunas plantas [...] el bullicio de los chicos jugando en los baldíos", pero donde durante las noches se hace notar el hacinamiento, la falta de camas, de colchones, de higiene y de comida, abundan los pisos de tierra, el frío y la lluvia que se filtra por los techos, alentando las enfermedades. Una realidad que Eva Perón identifica —en el discurso de confrontación que caracteriza al gobierno popular peronistacon "la expresión más sórdida y perversa del egoísmo de los ricos"."

Para el Presidente Juan Perón la inauguración de su gobierno el 4 de junio de 1946 representa "el triunfo del pueblo argentino", que dejaría "deslumbrados a los que vivían en la semipenumbra del interés creado"; aquéllos que forjaran "una atmósfera artificial a fuerza de repetir que somos un país rico y callar que eran extraordinariamente pobres las masas trabajadoras". ${ }^{12}$

Dos años más tarde y alentado por el rédito político obtenido a partir de esa "revolución de carácter económico, densa en realizaciones sociales", Perón no vacila en diagnosticar que "el tugurio infecto, la esposa famélica y envejecida por la labor agobiadora, los hijos depauperados, la falta de higiene, representan el ambiente propicio a la germinación del odio y con él, de la violencia". ${ }^{13}$ Sustentando así un discurso descriptivo, de lenguaje

10 Perón, Eva: La Razón de mi Vida, Buenos Aires, 1973, pág. 17.

11 Ibídem, págs. 128-131.

12 Cámara de Senadores de la Nación: Diario de Sesiones 1946, Buenos Aires, 1946, t.1, pág. 45. Girbal-Blacha, Noemí M.: "Reforma financiera y crédito a la producción: el caso del Banco de la Provincia de Buenos Aires, 1946-1950", Revista CICLOS en la historia, la economía y la sociedad, vol. 2, núm. 3, segundo semestre de 1992, págs. 73-94.

13 Cámara de Senadores de la Nación: Diario de Sesiones 1948, Buenos Aires, 1948, t.1, pág. 53. 
sencillo, claro, con un mensaje directo; aquél que mientras contrarresta cualquier avance comunista, va orientado a justificar sus concesiones en pro del mantenimiento del control social y del orden, tan caros a la élite dirigente y al gobierno nacional.

La pobreza se asocia a la falta de riqueza material propia de la Argentina pre-peronista y al mismo tiempo justifica la necesidad de lograr en la Nueva Argentina una redistribución equitativa de los bienes, que permita hacer realidad la "justicia social" y consolidar la "reforma social"; que — no obstante los anuncios- parece alcanzar un tope hacia los años de 1950, cuando el Estado implementa el "cambio de rumbo", revisa la política económica, escasean los acuerdos en materia de previsión social y se apela con insistencia a la racionalización. Entonces, el discurso que alienta la división de la sociedad argentina en dos bandos irreconciliables, peronistas y antiperonistas, pone énfasis reiterado en las realizaciones de la etapa próspera de la Nueva Argentina y deja de describir y caracterizar la pobreza, a la subcultura que representa, como un fenómeno preocupante en esos tiempos. ${ }^{14}$

Se prefiere asociar la pobreza, la miseria, la enfermedad y la angustia de la inseguridad con la desocupación, el desempleo y la imprevisión, que - por supuesto- no tienen cabida en la Argentina de Perón. ${ }^{15}$ En un discurso que insta a conservar los beneficios obtenidos, se advierte al mismo tiempo sobre las carencias del pasado y la necesidad de preservar lo que se tiene para consolidar el futuro, reclamando lealtades de parte de los beneficiarios directos de aquellas concesiones. Producir más y consumir menos es la consigna del momento.

Las definiciones y descripciones de la pobreza marchan unidas, para el oficialismo, a dos cuestiones clave: el enunciado de los medios para contrarrestarla y la valoración política que de ella se hace a partir de un discurso y de un mensaje que se alimenta de la contrastación entre la Nueva Argentina y la Argentina oligárquica; temas que se abordan a continuación para cumplir con el objetivo propuesto en este estudio: el de hacer un balance de la significación de la pobreza vista desde el escenario del poder que detenta el gobierno nacionalista y popular de Juan Domingo Perón, y hacerlo a la luz del análisis histórico.

14 Sidicaro, Ricardo: "Contribuciones para el estudio de las ideas políticas de Perón”, Estudios Sociales, 8, Santa Fe, primer semestre de 1995, págs. 31-48; y Girbal-Blacha, Noemí M.: "Mitos y realidades del nacionalismo económico peronista (1946-1955)" en Actas del Congreso de AHILA, tomo III, Liverpool, 1998, págs. 367-383.

15 Ianantuoni, Domingo Rafael: El Segundo Plan Quinquenal al alcance de los niños de 5to y 6to grados, Buenos Aires, 1953, págs. 7-9. 


\section{Los medios para contrarrestar la pobreza}

El antídoto para contrarrestar los males de la pobreza - conforme a los postulados de la doctrina peronista - es la "justicia social", que el Estado concreta asegurando el trabajo, la salud pública, la educación y la previsión y asistencia social. Cuenta para plasmar sus aspiraciones no sólo con una legislación dispuesta a asegurar esas proposiciones sino con el invalorable accionar de la Fundación de Ayuda Social María Eva Duarte de Perón, que obtiene personería jurídica el 8 de julio de 1948 con dicha finalidad asistencial, ${ }^{16}$ expresada a través de sus objetivos: 1) prestar ayuda pecuniaria o en especie "a toda persona carente de recursos que así lo solicite y que, a juicio de la fundadora, merezca ser otorgado"; 2) construir viviendas para su adjudicación a familias indigentes; 3) crear y/o construir establecimientos educacionales, hospitalarios, recreativos o de descanso conforme a sus fines; 4) construir establecimientos benéficos de cualquier índole, con o sin cargo al Estado nacional, provincial o municipal; y 5) propender, contribuir o colaborar por todos los medios a su alcance a la realización de obras de interés general y "que tiendan a satisfacer las necesidades esenciales para una vida digna de las clases sociales menos favorecidas". En suma, la enunciación de todo un programa contra la indigencia, la pobreza y el abandono social. Una propuesta que se materializa a través de obras que están destinadas "a los humildes, llenas de niños, de ancianos, de descamisados, un poco más felices que antes", afirma Eva Perón. ${ }^{17}$

A través de estos postulados se complementa la obra de "justicia social", la "justicia redistributiva", propuesta por Juan Perón en el discurso de proclamación de su candidatura a Presidente de la República, del 12 de febrero de 1946, cuando se muestra partidario de instrumentar las leyes "como un medio de progresar, pero de progresar todos, pobres y ricos, en vez de hacerlo solamente éstos a expensas del trabajador"; ${ }^{18}$ proyectando una línea de continuidad iniciada por él un bienio antes desde la Secretaría de Trabajo y Previsión.

El programa de acción "que se asienta sobre la voluntad de la mayoría y sobre el derecho de todas las familias a una vida decorosa, la que tiende a

16 Ferioli, Néstor: La Fundación Eva Perón/ 1, Buenos Aires, 1990.

17 Estatuto de la Fundación Eva Perón, Buenos Aires, 1950 (folleto); y Perón: La Razón de..., págs. 164-165.

18 Cámara de Senadores de la Nación: Diario de Sesiones 1946, Buenos Aires, 1946, t. 1, pág. 53. 
evitar el espectáculo de la miseria en medio de la abundancia", ${ }^{19}$ es enunciado tempranamente y en esa coyuntura por el entonces coronel Perón. Una vez más, usa un lenguaje simple y directo, que lo singulariza, para destacar que esa tarea es "la preocupación fundamental del Estado" que él lidera.

¿Cuáles son los medios propuestos para superar la pobreza?: "la elevación del nivel de vida hasta el standard compatible con la dignidad del hombre y el mejoramiento económico general"; la propulsión de organizaciones mutualistas y cooperativas; el incremento de la formación técnica y capacitación profesional; los préstamos para la construcción y renovación del hogar obrero, de la clase media, pequeños propietarios, rentistas y jubilados modestos, "y estímulo, fomento y desarrollo del vasto plan de seguridad social y mejoramiento de las condiciones generales de trabajo". ${ }^{20}$ Para concretar estas aspiraciones, el Estado cuenta desde julio de 1946 con el Consejo Económico Social, organismo asesor y coordinador en esas áreas de su competencia.

La pobreza se asocia siempre con la clase trabajadora, toda vez que para el peronismo su permanente referencia al "pueblo" se identifica con "el pueblo humilde, trabajador y descamisado", al que el propio Perón designará - a partir de 1950 - como "lo único permanente en el país", es decir, "la única base de sustentación para la unidad nacional", esencia de la "comunidad organizada". ${ }^{21}$

Ya en 1947 y como para dar muestras de que "la justicia ha de cumplirse inexorablemente, cueste lo que cueste y caiga quien caiga", ${ }^{22}$ el Presidente Perón informa ante la Asamblea Legislativa que, en materia de remuneraciones, el Estado fija un salario mínimo mensual de 200 pesos para los empleados y obreros nacionales y aumenta en un $15 \%$ los sueldos municipales menores de 300 pesos; amplía el régimen de previsión social a los enfermos y desocupados, consagra los Derechos del Trabajador, promueve la construcción de viviendas de tipo económico y barrios obreros y desarrolla el "turismo popular para el trabajador", al que conceptualiza como "una necesidad social". ${ }^{23}$

19 Ibídem, págs. 55-56.

20 Ibídem, pág. 58.

21 Cámara de Senadores de la Nación: Diario de Sesiones 1950, Buenos Aires, 1950, t.1, pág. 27.

22 Perón: La Razón de ...., pág. 145.

23 Cámara de Senadores de la Nación: Diario de Sesiones 1947, Buenos Aires, 1947, t.1, págs. 20-22. Del Campo, Hugo: Sindicalismo y peronismo. Los comienzos de un vínculo perdurable, Buenos Aires, 1983, págs. 120-169. 
El aumento en el nivel ocupacional de los obreros, que se eleva de 452.307 personas en 1937 a 846.111 en 1943 , y a 1.151 .309 en 1947 , es otra expresión de los logros en la lucha peronista contra la pobreza. Junto a esos logros, el oficialismo registra y divulga el aumento en los salarios que, tomando como base 100 para 1943, alcanza un índice de 271,9 para 1948 y le permite consignar al Presidente de la República el aumento de un 99,8 \% entre 1943 y 1947 para el salario medio de un obrero. Para afirmar el éxito de su política socioeconómica, el gobierno destaca que mientras el costo de vida ha crecido un 78,5\% entre 1939 y 1947, el salario medio ha aumentado, en igual período, un 102,3\%. Guarismos que el Estado hace corresponder con el afianzamiento paulatino de la industria nacional y a los que considera "una demostración evidente del resultado de la aplicación de las medidas legales tendientes a lograr una mayor justicia social.". ${ }^{24}$

La previsión también resulta un exponente del bienestar social y no sólo de la población activa, sino de quienes por razones de edad o incapacidad física no tienen posibilidades de trabajar. El Estado peronista atiende sus reclamos y necesidades. La ampliación del campo de aplicación del régimen jubilatorio indica que los aportes a las diferentes cajas se triplican entre 1943 y 1947, pasando de 213.000.000 de pesos en el primer año a 1.195.974.450 pesos en el segundo. El número de afiliados al Instituto Nacional de Previsión Social también crece, de 482.000 en 1943 a 3.245.000 un quinquenio más tarde. Una política previsional que se prolonga en el aumento de la capacidad de ahorro popular, cuyos depósitos en cajas de ahorros bancarias se triplican entre 1943 y 1948, año —este último- en que registran un total de 6.094.000.000 de pesos.

También la capacitación del obrero se desarrolla a través de múltiples iniciativas promovidas desde la Comisión Nacional de Aprendizaje y Orientación Profesional, el Instituto Técnico y la Universidad Obrera. En 1948 la existencia de 5 escuelas fábricas, 27 cursos de aprendizaje, 20 cursos de medio turno para varones y 2 para mujeres, 16 cursos profesionales femeninos, 20 cursos acelerados y 5 escuelas privadas de fábricas —además de los similares que promueve la Fundación Eva Perón- expresan en números el carácter de este aspecto del asistencialismo brindado a los sectores populares y no exento - en muchos casos- de un adoctrinamiento. ${ }^{25}$

24 Cámara de Senadores de la Nación: Diario de Sesiones 1948, Buenos Aires, 1948, t. 1, págs. 23-24.

25 Ibídem, págs.. 24-25; año 1949, pág. 33. 
A esos beneficios Perón les atribuye el aumento del rendimiento medio por hora trabajada por el obrero argentino.

Las medidas adoptadas por el Estado no sólo benefician a los habitantes del medio urbano. Se orientan también a dar seguridad al hombre de campo, a través de "salario, vivienda y comodidades suficientes como para evitar la migración en masa hacia las grandes ciudades." ${ }^{26} \mathrm{El}$ contexto y los objetivos no son nuevos y se orientan a hacer efectivo, como en décadas anteriores, el control social, ahora avalado por una legislación acorde a los tiempos (Estatuto del Peón Rural, 1944; Estatuto del Tambero Mediero, 1946; del Centro de Oficios Varios — luego FATRE— en 1947), que se prolonga desde 1950 en un incentivo directo al cooperativismo; aquél que no manifiesta una "mentalidad opuesta a la economía social justicialista", ${ }^{27}$ y que por entonces agrupa a unos 200.000 afiliados.

No obstante las resoluciones orientadas a radicar a la población rural en el campo, el crecimiento del Gran Buenos Aires es notorio, y si ya en 1937 Alejandro Bunge se refería al "grave problema del hogar de una sola pieza", cuando comprobaba que el $80 \%$ de las familias obreras que habitaban la planta urbana de la capital vivían hacinadas en una sola habitación, ${ }^{28}$ el censo de 1947 muestra que el problema es muy complejo y subsiste. Registra para la zona metropolitana de Buenos Aires 4.720.000 habitantes (26\% inmigrantes y $29 \%$ migrantes internos), con una concentración significativa en el Gran Buenos Aires: Avellaneda 273.839 habitantes, Lanús 249.473 y San Martín 269.514 habitantes, en estrecha relación con el proceso de industrialización creciente en el área.

La pobreza debe ser contrarrestada allí y en sus bases. El nacionalismo económico peronista orienta entonces sus inversiones hacia las obras públicas, fijando un orden de prioridades en relación con las exigencias populares. Del total de recursos dirigidos a promover estas obras, un $20 \%$ se destina a viviendas, otro $20 \%$ a obras hidráulicas, un $25 \%$ al transporte ferroviario y fluvial, un $5 \%$ a la provisión de agua potable, al igual que a escuelas y hospitales. ${ }^{29} \mathrm{El}$ número de pasajeros transportados por ferrocarril entre 1946 y 1950 se duplica, a la par que la Corporación de Transportes de la Ciudad de Buenos Aires ve crecer de 1.713.000.000 a

26 Ibídem, año 1948, t. 1, pág. 29.

27 Ibídem, año 1952, t.1, págs. 25-26. Girbal-Blacha, Noemí M.: Ayer y hoy de la Argentina rural. Gritos y susurros del poder económico (1880-1997), Buenos Aires, 1998, págs. 52-74.

28 Palacios, Alfredo L.: El dolor argentino, Buenos Aires, 1938, págs. 141-143.

29 Cámara de Senadores de la Nación: Diario de Sesiones 1949, Buenos Aires, 1949, t. 1, págs. 28 y 31 . 
2.434.000.000 el número de pasajeros que transporta en igual período, como una muestra del dinamismo socioeconómico que convoca a todos los sectores de la población en la Argentina de fines de la década del ' 40.

En materia de salud pública también se advierten adelantos. "El Estado debe afrontar la asistencia médica integral en beneficio de aquellos que ganan menos", afirma en su capítulo XII el Manual del Peronista. Se hace referencia a una inversión en salud pública bien organizada, que sólo tenga como límite "la cura de todos los enfermos que el país tiene" ${ }^{30} \mathrm{~A}$ propósito, en 1949 es el propio Presidente Perón quien, al inaugurar las sesiones legislativas, da cuenta de la instalación de 7 hospitales regionales con 400 camas y 30 micro-hospitales rurales, así como la ampliación de pabellones y servicios en los ya existentes. La organización del transporte aéreo de enfermos, mediante 12 aviones-ambulancia que trabajan en coordinación con 100 ambulancias terrestres distribuidas en todo el país; el funcionamiento de 5 maternidades y la habilitación de 50 Centros de Maternidad e Infancia en zonas alejadas, que se suman a otros 60 que se reorientarán con brevedad, son algunas concreciones que procuran dar satisfacción a los múltiples pedidos formulados por reparticiones públicas y particulares. ${ }^{31}$

La creación del Instituto Nacional de Hemoterapia (1947), la instalación del Hospital Nacional de Odontología y de unos 60 consultorios odontológicos, la campaña antipalúdica y la lucha contra el cáncer a partir de un diagnóstico precoz, la educación sanitaria popular y el tratamiento con equipamiento de última generación, también son algunas muestras de la tarea realizada por el gobierno para combatir, desde esta perspectiva, la pobreza y la desprotección de los sectores más bajos de la población. ${ }^{32} \mathrm{La}$ atención del enfermo se considera un asunto fundamental en la consolidación de la familia, y por esta razón en 1950 el país cuenta con 21 hospitales y policlínicos de reciente creación, con un total de 22.650 camas, distribuidos en todo el espacio territorial argentino. A ellos se suman los 19 hogares escuelas creados por la Fundación, que tienen capacidad para albergar a 25.320 niños en todo el país y varios hogares de tránsito que para 1949 — a un año de su creación — han atendido más de 60.000 casos. ${ }^{33}$

30 Manual del ....., págs. 30-31.

31 Archivo General de la Nación (en adelante, AGN): Fondo documental Secretaría Técnica 1a. y 2a. Presidencia del Teniente General Juan Domingo Perón (1946-1955), año 1951, legajos 013, 024, 392, 396; años 1951-53, legajos 045, 047, 092, 119, 189, 305, 318, 337, 348, 383, 443 у 492.

32 Cámara de Senadores de la Nación: Diario de Sesiones 1949, Buenos Aires, 1949, t.1, págs. 31-32. La Nación Argentina Justa, Libre, Soberana, Buenos Aires, 1950, 3era. edición, pág. 199.

33 Ibídem, págs. 197-199 y 202. 
Hacia 1949 el gobierno de Juan Domingo Perón reconoce que, si bien el incremento salarial es un hecho en la Nueva Argentina, también lo es el aumento en el costo de vida, que para ese año estima en un 12,5\%. La justificación del aumento de circulante — que se relaciona con la reforma de la Carta Orgánica del Banco Central, que a partir de 1949 desliga la emisión fiduciaria del respaldo en oro $^{-34}$ encuentra una explicación contundente "en la dignificación de los trabajadores", en la baja de los niveles de pobreza entre los sectores populares, en la satisfacción de sus necesidades de vivienda, ropa, trabajo, medicamentos y máquinas de coser, reclamados una y otra vez en la correspondencia dirigida al gobierno y a la Fundación Eva Perón. Dicho con palabras de Evita, el propósito es que los pobres "se acostumbren a vivir como ricos (...) que se sientan dignos de vivir en la mayor riqueza", de ahí que en los "hogares" administrados por la Fundación — como Eva Perón proponía - "ningún descamisado debe sentirse pobre. Por eso no hay uniformes denigrantes. Todo debe ser familiar, hogareño, amable". ${ }^{35}$

$\mathrm{Al}$ filo de los años '50, desde el Estado peronista, aunque se destaca la celebración de 243 convenios colectivos de trabajo que benefician a 3 millones de trabajadores, se anuncian tiempos de "racionalización económica" para incrementar la renta nacional, que en 1943 se calculaba en \$12.000.000.000 y en 1948 se estima en unos \$31.000.000.000, y llegar "a la expansión del bienestar general"; con un ingreso anual per cápita de $\$ 800$ para el primer año y de $\$ 1.900$ para el segundo. Se apela entonces a una propuesta directa: mantener alto el nivel de ahorro nacional y su tasa de inversión, para conservar el nivel de empleo y "por esto no pueden dolernos los sacrificios que nos impone satisfacerlo", afirma Perón; reclamando la lealtad popular sin dejar de reconocer a la justicia social como "el gran objetivo de nuestro movimiento" ${ }^{36}$ amparado desde entonces en los principios de la "doctrina nacional". Mientras tanto, por diversos medios de información y divulgación se insiste en que el "Presidente de la República General Juan Perón aconseja producir más y consumir menos". ${ }^{37}$

El cambio de rumbo en la economía argentina, a partir de 1950, promueve desde 1951 los reclamos de particulares e instituciones públicas en

34 Girbal-Blacha: "Diagnóstico, legislación financiera...”, págs. 155-198.

35 Perón, Eva: La Razón de ..., págs. 169 y 183. Cámara de Senadores de la Nación: Diario de Sesiones 1949, Buenos Aires, 1949, t.1, págs. 33-37. La Nación Argentina Justa, ..., págs. 197-198.

36 Cámara de Senadores de la Nación: Diario de Sesiones 1949, Buenos Aires, t.1, 1949, pág. 37; año 1950, pág. 7; año 1951, pág. 38.

37 Casas, Blanca Alicia: El Alma Tutelar. Libro de lectura para primer grado superior, Buenos Aires, 1954, 4. ${ }^{a}$ edición, pág. 45. 
favor de la construcción de barrios obreros, casas baratas, cooperativas constructoras de viviendas y control de los alquileres frente al déficit habitacional $;^{38}$ solicitudes que inciden en el discurso oficial que insiste más en rescatar los logros del camino recorrido que en señalar con precisión la acción anual de gobierno; se hace corriente la referencia a la necesidad de "consolidar la reforma social". En tal sentido, es en 1952 cuando el oficialismo reseña las cifras invertidas en el marco del Primer Plan Quinquenal, con prioridad social, al destacar los $\$ 960.000 .000$ dedicados a vivienda, \$1.250.000.000 a educación, \$500.000.000 a salud pública, $\$ 2.300 .000 .000$ a transportes y $\$ 1.150 .000 .000$ invertidos en vialidad. ${ }^{39}$

En tanto rescata, de forma especial, "la acción que por las familias humildes de nuestro pueblo" desarrolla la Fundación de Ayuda Social María Eva Duarte de Perón apela a los réditos derivados de la solidaridad popular y de la unidad nacional, al mismo tiempo que revaloriza los beneficios de contar con fuerzas de trabajo organizadas, así como las ventajas de la economía social; mientras avanza hacia un virulento discurso de confrontación entre pobres y ricos, peronistas y antiperonistas, que advierte al tiempo que descalifica y obliga a definir posiciones frente a la política justicialista. "Buscamos hacer desaparecer toda causa de anarquía para asegurar con una armonía, a base de justicia social, la imposibilidad de alteración de nuestras buenas relaciones entre el capital, el trabajo y el Estado", recuerda Perón a la sociedad en su conjunto y a los opositores en especial. ${ }^{40}$

En mayo de 1953 el balance de la gestión en materia de política social, que Perón formula frente a la Asamblea Legislativa, confirma lo expuesto. Dice entonces que hasta 1943 los obreros defendían su salario a través de la huelga sin mucho éxito; entre 1943-46 los reclamos siguieron y fueron oídos sin apelar con frecuencia a medidas de fuerza, en tanto "se fueron imponiendo los principios de justicia social que contiene la doctrina peronista"; en 1953 — afirma Perón en momentos en que se dispone a anunciar el Segundo Plan Quinquenal_ " "los trabajadores no piden incrementos de salarios. Sólo exigen justicia”. El objetivo del discurso, que aparece envuelto aún en los ecos del Plan de Emergencia Económica de 1952, es claro, y lo expone el propio Presidente de la Nación sin rodeos: "lograr

38 AGN: Fondo documental Secretaría Técnica ..., año 1951, legajos 021 y 024; años 1951-54, legajos 033, 035, 053; años 1951-52, legajos 071, 145, 178, 245, 296, 326, 335, 344 y 405.

39 Cámara de Senadores de la Nación: Diario de Sesiones 1952, Buenos Aires, 1952, t.1, pág. 23.

40 La Nación Argentina Justa, ..., pág. 147. 
la más absoluta solidaridad del pueblo argentino", ${ }^{41}$ en tiempos de reajustes, falta de empleo, deterioro salarial, reglamentación de convenios colectivos de trabajo y apertura de nuevas fuentes laborales; ${ }^{42}$ pero cuando aún se mantienen los logros de la "revolución social" iniciada en 1943, y Perón se dispone a entregar a ese pueblo "las banderas verticales de la justicia social, de la independencia económica y de la soberanía política". ${ }^{43}$

Por entonces, un libro de lectura para niños que están iniciando la escolaridad primaria recuerda a estas generaciones infantiles, a través de una ilustración y un breve texto, que "ese es un obrero argentino. Sale cantando de la fábrica donde trabaja y camina con prisa, hacia su otra obligación: la escuela. Tiene buen sueldo, vacaciones pagas, aguinaldo, asistencia médica y la vejez asegurada con la jubilación". ${ }^{44}$ Podría decirse que en esta Argentina la pobreza es un mal recuerdo. Los reclamos populares que llegan a través de una nutrida correspondencia dirigida a la Presidencia de la Nación ${ }^{45}$ y los datos del Censo Nacional de 1960 muestran que aún queda mucho por hacer; que se ha avanzado, pero que la marginalidad sólo ha retrocedido para tomar impulso y crecer.

\section{Valoración política de los pobres, los humildes, los descamisados}

"Un día oí por primera vez de labios de un hombre de trabajo que había pobres porque los ricos eran demasiado ricos; y aquella revelación me produjo una impresión muy fuerte", expone Eva Perón en las páginas de La Razón de mi Vida, en los albores de la década de $1950 .{ }^{46} \mathrm{Su}$ origen humilde, la identificación de esta causa con la causa de Perón, inaugurada a partir de su gestión al frente de la Secretaría de Trabajo y Previsión, y su accionar desde la Fundación de Ayuda Social hacen de Eva Perón "la dama de la esperanza", "la revolucionaria", "la mujer del mito", pero esencial-

41 Cámara de Senadores de la Nación: Diario de Sesiones 1953, Buenos Aires, 1953, t. 1, págs. 21 y 26.

42 AGN: Fondo documental Secretaría Técnica ..., años 1946-47, legajos 466, 467, 468, 502, 512 y 583; años 1951-52, legajos 043, 088, 146, 184, 257, 327 y 351; año 1952, legajos 503, 585 y 586; año 1953, legajos 457-458; años 1953 a 1955, legajos 581, 582, 587, 588, 590, 591, 593, 594, 595 y 669.

43 Cámara de Senadores de la Nación: Diario de Sesiones 1954, Buenos Aires, 1954, t.1, pág. 14.

44 Casas: El Alma ..., pág. 72.

45 Información detallada en AGN: Fondo documental Secretaría Técnica ..., índice.

46 Perón: La Razón de ..., pág. 17. 
mente "la abanderada de los humildes"; y de su función una "misión de intermediaria entre los humildes y Perón". De ahí que las llamadas por entonces "células mínimas" — las colaboradoras barriales - ejerzan una función primordial para llegar aun a los lugares más apartados con el beneficio de la asistencia social. ${ }^{47}$

Para el Estado peronista la pobreza es símbolo de contraste entre la Argentina de "la opresión oligárquica"y la "Nueva Argentina" que brega —desde la doctrinaria "justicia social" - por "salarios justos y condiciones dignas de trabajo" y por satisfacer la "falta de vivienda, vestidos, salud", ${ }^{48}$ a través de un acercamiento paternalista y personal del poder político hacia los sectores populares.

La lucha contra la pobreza — con toda la carga simbólica que ella encierra- es la razón de ser y la expresión de la "justicia social" propuesta por la doctrina peronista. "No es filantropía ni es caridad, ni es limosna, ni es solidaridad social, ni es beneficencia. Ni siquiera es ayuda social [...] Para mí es estrictamente justicia", afirma Eva Perón, en su preocupación por distinguir su tarea de la que tradicionalmente desempeñaran "las decadentes damas de la Sociedad de Beneficencia", quienes a su juicio hacen de la caridad que brindan "un placer de los ricos"; toda vez que desconocen las necesidades de los pobres, añade Evita en un discurso que confronta, desafía, denigra y descalifica al oponente. ${ }^{49}$

Para la esposa del primer mandatario, pedirle ayuda a ella "y pedir a Perón no es humillante para nadie, ni para los más encumbrados. Menos para un descamisado que ve en él a un padre." ${ }^{50}$ De ahí la importancia de prestar ayuda a este sector de la población que será, a corto plazo, la columna vertebral del movimiento justicialista. La referencia a los pobres, a los descamisados, a los humildes, está siempre dirigida a marcar diferencias entre la Argentina preperonista y la liderada por el presidente Juan Perón. El contraste es su nota distintiva: los hogares no son asilos, "los Hospitales no son antesalas de la muerte", las viviendas no son lugares para dormir "sino para vivir alegremente"; viejas costumbres que en la "Nueva Argentina" se atribuyen a que "todo en la "obra social" del siglo que nos precedió fue así: frío, sórdido, mezquino y egoísta." La oligarquía resulta

47 Ibídem, pág. 143. La Nación Argentina Justa, ..., pág. 195. Taylor, J.M.: Evita Perón. Los mitos de una mujer, Buenos Aires, 1981.

48 Perón: La Razón de ..., págs. 133-135.

49 Ibídem, págs. 147-149 y 175.

50 Ibídem, pág. 151. 
en este discurso responsable de todos los males de la sociedad argentina. "Ellos — dice sin rodeos Eva Perón- los hicieron comunistas [a los niños] poniéndoles un uniforme gris, dándoles de comer un solo plato, cerrándoles todas las puertas de la dicha humana, de la simple dicha que es tener un hogar o una imitación del hogar por lo menos." ${ }^{51}$

El contraste es la nota permanente que se trasunta tanto en las imágenes como en el discurso peronista, que asume, en varias ocasiones, un carácter desafiante y emplea un lenguaje que denigra al oponente, en tanto conforta y protege al desamparado y al "compañero" de la causa justicialista. La misma Eva Perón se encarga de darle esa connotación cuando refiriéndose a los pobres afirma: "yo deseo que se acostumbren a vivir como ricos ... que se sientan dignos de vivir en la mayor riqueza", es decir, en una riqueza diferente, aquélla que es capaz de dignificar, como la que propone la Argentina peronista, donde —además - esos ricos tengan "alma de pobres: humilde, limpia, sencilla." ${ }_{52}$

Los afiches, folletos de difusión y bibliografía de propaganda de la acción de gobierno reproducen imágenes grisáceas, tristes, agobiadas y escuálidas de hombres, mujeres y niños de la sociedad argentina anterior a 1943. Es cuando el empleo escasea, los sueldos se pagan con atraso, las viviendas son precarias e insuficientes, los precios aumentan y el malestar social se generaliza y se hace más virulento, sostiene el peronismo en su discurso y en su mensaje dirigido a la sociedad en su conjunto. La fotografía de la situación contrasta con las imágenes que allí se hacen corresponder con la Argentina peronista, donde no hay mendicidad, ni ollas populares, no hay desempleo y el bienestar social se difunde y se afirma. La vida del obrero argentino se muestra como símbolo de éxito, prosperidad y alegría a través de la propaganda oficial, cuando Juan Perón afirma y sostiene con su accionar lo que los sectores populares quieren oir; es decir, que "ningún habitante que trabaja debe ganar menos de lo que necesita para vivir." ${ }_{53}$

El discurso también se esfuerza por negar la connotación política que este asistencialismo de hecho encierra. Para expresarlo en palabras de Eva Perón: "yo no niego que mis obras ayuden a consolidar el enorme prestigio político del general, pero nunca he subordinado el amor al interés ... y menos tratándose de mi pueblo"; ${ }^{4}$ dando muestras de sus dotes de lider

51 Ibídem, págs.167-168.

52 Ibídem, pág. 169.

53 La Nación Argentina Justa, ..., págs. 34, 48-49, 184-185, 188-189 y 194.

54 Ibídem, pág. 175. 
popular, personalista, con una gran capacidad organizadora pero también manipuladora, haciendo uso de un despliegue de mecanismos de articulación y comunicación entre el líder y la clientela política, en base a un paternalismo capaz de garantizar el cumplimiento de los anhelos populares. ${ }^{55}$

\section{Un balance a la luz del análisis histórico}

Como bien propone el antropólogo estadounidense Oscar Lewis al analizar la sociedad mexicana en los niveles marginales entre 1947 y 1958, permitiéndole escribir su magnífica Antropología de la pobreza, también en la Argentina peronista, como en otras naciones modernas de entonces, la pobreza es un factor dinámico; sugiere antagonismos intersectoriales, implica problemas sociales y necesidad de cambios. El peronismo asume su causa y deja registro de todas esas cuestiones. Mide y define la pobreza, la confronta a su opuesto: la riqueza; articula su doctrina y su política sobre ese eje, adopta gran parte de los símbolos de esta subcultura, utilizando su lenguaje, sus gestos, sus paradigmas, y opera los cambios, que precisa y difunde por contraste.

Le da envergadura política y hace de ella el sello capaz de singularizar los perfiles de la "Nueva Argentina" en oposición a la "Argentina de los privilegios", que la precediera; simplemente haciéndose eco de los anhelos y las necesidades de los obreros, de los humildes, de los descamisados. Sabe escuchar y transmitir ese legado, con un objetivo muy preciso que condensa en una selección de la obra máxima de la tradición gauchesca: el Martín Fierro, usándola para ilustrar uno de los tantos afiches de propaganda que muestra gráficamente una Argentina injusta, oligárquica y opresora. Se afirma en ese texto: "Tiene el gaucho que aguantar/ hasta que lo trague el "oyo"/ o hasta que venga algún criollo/ en esta tierra a mandar".

La hora parece haber llegado de la mano de Juan Domingo Perón y la "justicia social". En medio de la crisis del discurso liberal argentino, Perón se apropia de las críticas al liberalismo y las transforma en ese discurso de confrontación al que se hizo referencia; introduce cambios, pero rescata continuidades con la tradición política argentina. ${ }^{56}$ Polemiza con los opo-

55 Álvarez Junco, José y González Leandri, Ricardo (compiladores): El populismo en España y América, Madrid, 1994, págs. 44-54.

56 Halperin Donghi, Tulio: "El lugar del peronismo en la tradición política argentina", en Amaral, Samuel y Plotkin, Mariano (compiladores): Perón del exilio al poder, Buenos Aires, 1993, págs. 15-44. 
sitores y a cada paso calcula los efectos ideológicos y políticos de su acción discursiva, que siempre toma muy en cuenta el ámbito donde se pronuncia, para capitalizar al máximo el efecto emocional y su valor simbólico para forjar la memoria colectiva. Revaloriza el sentido de algunas palabras que por lo común se identifican con la descalificación del que las recibe. Así, el pueblo se convierte en "pueblo trabajador", digno y heredero auténtico del futuro, Perón es el "primer trabajador" y se considera a sí mismo y ante la sociedad como un descamisado; para el discurso evitista — en cambio- Perón es siempre "glorioso" y "padre de todos los argentinos". La oligarquía - a su vez- es "egoísta y vendepatria". Eva Perón, usando un lenguaje casi de radionovela, se califica a sí misma como una mujer "humilde" y "débil", haciendo gala de un ritual que revitaliza el sentimiento de colectividad.

Atento a estos ritos, el peronismo comienza a contrarrestar los efectos no deseados de una pobreza a la cual no es ajena la Argentina preperonista, pero que — sin duda - desde mediados de la década del ' 40 adquiere un despliegue político y un grado de conciencia social desconocidos hasta entonces. Perón recoge las experiencias privadas de los trabajadores y las hace públicas, afirmando sus valores, su estilo de vida; dando a ese sector mayoritario de la sociedad "la dignidad simbólica de ser alguien", ${ }^{57}$ y en ese contexto, la pobreza adquiere un papel de primer orden, al tiempo que se convierte en eje del accionar nacionalista y popular de la gestión gubernativa liderada por Juan Perón.

El peronismo es "un conglomerado polifacético de legados y transformaciones" que provienen de las luchas sociales que lo precedieron y - como ha expuesto recientemente Natalio Botana - muestra un "paternalismo transgresor" que esgrime un "lenguaje guerrero y combatiente". ${ }^{58}$ Pero, la singularidad de la prosperidad peronista es que se torna palpable para el hombre común y, especialmente, para los sectores sociales más pobres.

Entre 1946 y 1948 la economía argentina da muestras de esa prosperidad, con una tasa de crecimiento promedio de la producción anual de un $8,4 \%$. Pero no es sólo ese aumento lo que hace del peronismo una etapa atípica de la historia que el país había vivido hasta entonces. Una distribución más equitativa de la riqueza, el aumento en los salarios obreros —en

57 De la Torre, Carlos: "Los significados ambiguos de los populismos latinoamericanos", en Álvarez Junco y González Leandri (compiladores): El populismo en ..., pág. 58.

58 Botana, Natalio R.: El siglo de la libertad y el miedo, Buenos Aires, 1998, pág. 237. 
1948, un $50 \%$ superior a los de 1945 —, 59 la vigencia de precios máximos al consumidor, el congelamiento de los alquileres y un mejor standard de vida, muestran a cualquiera que quiera verlo un espectáculo de prosperidad popular; por lo menos hasta los años ' 50 cuando el estado peronista enarbole las banderas de la austeridad y la productividad como condición esencial para contrarrestar postergaciones y retrocesos en el campo de la "justicia social".

59 Gerchunoff y Llach: El ciclo de ..., pág. 181. 